\title{
El testimonio como estrategia política para visibilizar la Violencia contra las Mujeres
}

\author{
Jessica Gutiérrez Gómez*
}

\begin{abstract}
Resumen
Este trabajo tiene como objetivo realizar un recuento acerca de cómo el movimiento de mujeres retomó el testimonio de víctimas como estrategia para hacer escuchar sus demandas de reconocimiento y justicia en el tema de violencia contra las mujeres. Se divide en tres momentos: la revisión de "la era del testigo" y cómo se legitiman socialmente los relatos de las víctimas; las acciones implementadas por las feministas que representan ONGs para ser escuchadas en los organismos internacionales de Derechos Humanos; y las dos perspectivas que articulan la demanda de justicia: la perspectiva penal y la sanitaria, específicamente analizadas en el caso de la violencia sexual a través del ejemplo de la política anti-trata. Finalmente, se retoman algunas críticas a esta estrategia y a las perspectivas planteadas.
\end{abstract}

Palabras clave: violencia contra las mujeres- testimonio-violencia sexualperspectivas-políticas públicas.

\section{Abstract}

This paper aims to conduct a review of how the women's movement used the testimony of victims as a strategy to make their demands for recognition and justice on the issue of violence against women heard. It is divided into three parts: A review of "the age of the witness" and how the accounts of victims are socially legitimized; the actions implemented by feminists representing NGOs in order to be heard by international human rights organisms; and the two perspectives from which the demand for justice is articulated: those of criminal punishment and healthcare, which are analyzed specifically respect to cases of sexual violence. Finally, some criticisms of this strategy and the perspectives presented are presented.

Key words: violence against women-testimony-sexual violenceperspectives -public policy.

*Licenciada en Psicología. CONICET/IIEGE- UBA. Contacto:jeministe@hotmail.com

Gutiérrez Gómez, Jessica "El testimonio como estrategia política para visibilizar la Violencia contra las Mujeres", en Zona Franca. Revista del Centro de estudios Interdisciplinario sobre las Mujeres, y de la Maestría poder y sociedad desde la perspectiva de Género, №24, 2016 pp. 38-63. ISSN, 2545-6504

Recibido: 25 de abril de 2016; Aceptado: 03 de julio 2016

Revista Zona Franca- Centro de estudios interdisciplinario sobre las mujeres (CEIM)- Maestría poder y sociedad desde la perspectiva de género (MG), Rosario, Argentina. ISSN, 2545-6504 http://zonafranca.unr.edu.ar/index.php/ZonaFranca| Numero 24 (2016). 
Diversos testimonios difundidos por instituciones u ONGs que trabajan bajo el paraguas de la política anti-trata en América Latina presentan imágenes o testimonios donde dejan ver que la única relación posible con el sexo comercial es la violencia. De igual manera, llama la atención el uso cada vez más frecuente de los testimonios relacionados con experiencias de sufrimiento en las políticas públicas de género, específicamente las que tienen como objetivo prevenir y atender la violencia contra las mujeres (VCM) ${ }^{1}$. En este sentido, se reflexionará sobre la importancia que adquieren dichos testimonios para visibilizara los sujetos víctimas y de qué manara el movimiento de mujeres los retomó como estrategia para introducirse en el terreno de los Derechos Humanos a nivel internacional e implementar programas y políticas públicas. Consideramos que dentro de esos testimonios, una de las estrategias principales consistió en resaltar aquellos asociados a la violencia sexual. Por ello analizamos, a manera de ejemplo, la política contra la trata de personas, interpretada y promovida por algunos grupos feministas abolicionistas como una herramienta para garantizar la protección de los Derechos Humanos de las Mujeres, cuando es en realidad el resultado de una política criminal. Para poder entender cómo se construyó esa relación se plantean las siguientes interrogantes: ¿Cuál es el papel que tiene el testimonio en las políticas de género? ¿Qué lenguajes comparten en común la construcción de víctimas del holocausto y la violencia de género? ¿De qué manera influyó “la era del testigo" en los discursos y reivindicaciones feministas en la lucha por garantizar un espacio en la agenda internacional de Derechos Humanos? ¿Cómo llegó a comprenderse la prostitución como un tipo de violencia contra las mujeres para

\footnotetext{
${ }^{1}$ VCM de aquí en adelante

Revista Zona Franca- Centro de estudios interdisciplinario sobre las mujeres (CEIM)- Maestría poder y sociedad desde la perspectiva de género (MG), Rosario, Argentina. ISSN, 2545-6504 http://zonafranca.unr.edu.ar/index.php/ZonaFranca| Numero 24 (2016). 
los instrumentos legales y de DDHHH internacionales? ¿Cuáles han sido las consecuencias de las políticas que resaltan a las mujeres que viven violencia como sujetos-victimas? ¿Cómo influyó esto en las políticas anti-trata? Evidentemente, estas preguntas rebasan el espectro de alcance de este artículo, por tanto, el foco principal es entender el uso del testimonio de las víctimas para las políticas públicas de género, en su relación con la violencia contra las mujeres (VCM). Para ello, este trabajo realiza brevemente un recorrido que no pretende ser lineal sino referencial, dividido en tres momentos. En primer lugar, se aborda la importancia que tiene el testimonio en la memoria colectiva como "ruptura de silencio" de los sobrevivientes (Calveiro, 2006). Se señala cómo se instala la "era del testigo" (Wioviorka, 1998 en Chevalier, 2000) y cómo se legitima el discurso de las víctimas a través de los relatos de experiencias en los juicios de verdad del holocausto, lugar donde se institucionalizó el sujeto-víctima. En un segundo momento, se muestra como algunas ONGs integrantes del movimiento de mujeres de los años 90's utilizaron como estrategia llevar testimonios de víctimas de violencia a los organismos internacionales de Derechos Humanos para que escucharan sus demandas con respecto a la VCM y así instalar políticas de género en sus contextos locales para prevenirla yerradicarla. Tal es el caso de los 33 testimonios de mujeres expuestos en el "Tribunal Global de violaciones de los Derechos Humanos de las Mujeres" ${ }^{2}$ en Viena en 1993, que sirvieron de antesala para la Conferencia Mundial sobre la Mujer en Beijín realizada en 1995.

\footnotetext{
${ }^{2}$ En "Testimonies of the Global Tribunal on Violations of Women's Human Rights" (Reilly et. al., 1994) aparecen completos los testimonios de las 33 mujeres de 25 países distintos.
} 
En un tercer momento, analizamos la lucha contra la violencia sexual entendida como VCM a través de la perspectiva penal y sanitaria. Para ejemplificar cómo operaron dichas perspectivas, se analiza en este trabajo el caso específico de la ligazón entre prostitución y violencia sexual y la creación de la política anti-trata. A lo largo del texto, se aborda el viraje sobre la importancia del testimonio en primera persona (de los sobrevivientes), al testimonio de los expertos que tienen contacto con las víctimas, especialmente el de los profesionales psi: psiquiatras y psicólogos. Finalmente, se realiza a manera de reflexión más que de conclusión, algunas críticas sobre estas estrategias y perspectivas en cuanto al uso político de los discursos de la VCM.

\section{Testimonio}

El siglo XX se conoce como "La era del testigo" (Wioviorka, 2006 en Chevalier, 2000) debido a la legitimación que adquirieron las narraciones de las víctimas sobrevivientes de procesos traumáticos. Entendiendo aquí el trauma no como una herramienta del discurso clínico, sino como "instrumento en la producción de testimonio sobre la base de la experiencia violenta" (Fassin, 2008:538).Lo que dota de contenido a los testimonios, en el marco de las declaraciones, es una narrativa en primera persona que contiene silencios, distorsión, confusión y terror; estos elementos se comprenden como indicios del carácter traumático.

Existe toda una línea de Studies Holocausto que incluyen diversas perspectivas de análisis para elaborar el tema del testimonio. Estos estudios 
también han sido producidos en América Latina ${ }^{3}$, acompañados de los denominados estudios de memoria colectiva para dar cuenta de los procesos de violencia de Estado de la región. Blanes y Palazón explican que no hay un consenso sobre la definición de testimonio, sin embargo se sabe que ha servido en las últimas décadas: "para nombrar prácticas culturales de denuncia y disidencia política, ligadas a proyectos de visibilización de colectivos y situaciones ignoradas por las narrativas y medios oficiales" (2015:1). Nos interesan en este punto, sobre todo aquellos desarrollados por Gabriel Gatti (2003, 2015) que han problematizado la representación de las víctimas, el protagonismo que han adquirido éstas en los últimos años y el testimonio como herramienta discursiva para hacerse escuchar.

Esta dupla entre testimonio, y "una víctima empoderada para denunciar en un juicio, definieron la sensibilidad del siglo XX" (Emmelhainz, 2015).Ello a través de la articulación víctima-testigo que se construyó con la suma de tres elementos: la propagación de audiovisuales de los campos de concentración nazi, la difusión de materiales escritos que incluían historias en primera persona o producciones teóricas; y los testimonios orales en los juicios. Estos testimonios colectivos por demandas de justicia "se erigieron como portadores de historia y de memoria de diversos proceso políticos"(Blanes, 2011:48).

Es interesante el rastreo que realiza Diddier Fassin (2008) para explicar el origen etimológico de testigo. Cita el trabajo de E. Benveniste, quien diferencia entre testis (testigo), aquel que está fuera de la escena pero observó el evento y por tanto su mirada objetiva puede ayudar a resolver el conflicto; y

\footnotetext{
${ }^{3} \mathrm{Si}$ se quiere ahondar sobre estos estudios es recomendable ver Blanes y Palazón (2015) donde se hace un recuento sobre Holocausto Studies pero sobre todo en cómo se han desarrollado los estudios sobre testimonio en América Latina.
}

Revista Zona Franca- Centro de estudios interdisciplinario sobre las mujeres (CEIM)- Maestría poder y sociedad desde la perspectiva de género (MG), Rosario, Argentina. ISSN, 2545-6504 http://zonafranca.unr.edu.ar/index.php/ZonaFranca| Numero 24 (2016). 
superotes (sobreviviente), que es aquel que lo experimentó directamente y tiene una visión subjetiva del mismo. Fassin muestra cómo la diferencia entre objetivo y subjetivo se fue dirimiendo con el tiempo, sobre todo en su relación con la búsqueda de verdad jurídica. Es así que el testimonio de los sobrevivientes ${ }^{4}$ se consideraba más objetivo para reconstruir las características de un conflicto violento pero en un segundo momento, el testimonio que se priorizaba era el de aquellos que tenían contacto con los sobrevivientes (agentes humanitarios o psicólogos). Un ejemplo de ello son los agentes humanitarios en conflictos de guerra, quienes cambiaron la consigna de "actuar y no hablar" por la de "actuar y hablar", es decir, que proporcionan atención a las víctimas y brindaban testimonio sobre su experiencia. Su objetivo no es brindar elementos para construir una verdad objetiva de los hechos sino dar cuenta de la verdad subjetiva de la experiencia de las víctimas ${ }^{5}$. Este elemento legitimó la voz de aquellos que documentan las experiencias sufrientes de los otros, ya que "se erigen como portavoces de los oprimidos para hacer público su sufrimiento [y] la esencia de su testimonio es más emocional que analítica" (Fassin, ídem: 537).

Más adelante, volveremos sobre este punto al analizar el papel de los profesionales psi que se erigen como expertos en el tema de las políticas públicas de violencia de género, y en algunos casos como testigos, hablando en nombre de las víctimas que asisten.

\footnotetext{
${ }^{4}$ Podían ser sobrevivientes del holocausto, pero posteriormente relacionamos esta categoría con la persona que "sobrevivió" cualquier evento de carácter violento, por ejemplo: conflictos armados, represión política en procesos dictatoriales o violencia de género.

${ }^{5}$ Lo anterior puede verse en la página oficial de Médicos sin Fronteras donde cada agente humanitario narra su experiencia en un apartado especial que dice textualmente "testimonio": https://www.msf.org.ar/actualidad/desde-el-terreno

Revista Zona Franca- Centro de estudios interdisciplinario sobre las mujeres (CEIM)- Maestría poder y sociedad desde la perspectiva de género (MG), Rosario, Argentina. ISSN, 2545-6504 http://zonafranca.unr.edu.ar/index.php/ZonaFranca| Numero 24 (2016). 


\section{VCM y el uso de los testimonios de las víctimas}

Es importante subrayar cómo el movimiento de mujeres al igual que otros colectivos, se nutrieron de la experiencia de contar testimonios para hacer escuchar sus demandas en los organismos internacionales de Derechos Humanos. Algunas autoras de diversas latitudes y provenientes de diferentes líneas del feminismo han reconstruido históricamente de qué manera fue el proceso de reconocimiento de la violencia contra las mujeres (VCM) en las esferas supra y transnacional (Mohanthy, 2008; Kapur, 2006). También han realizado un balance sobre las ventajas y desventajas de traducir la mayoría de sus demandas de justicia en esos términos (Pitch, 2003 y 2014) y han resaltado el énfasis que se hizo en la violencia sexual (Miller, 2004). A continuación se realiza una síntesis breve de dicho recorrido.

El feminismo de los 70's a través de los pequeños grupos de autoconciencia en Estados Unidos -después retomados en algunos contextos latinoamericanos (García y Valdivieso, 2005)-, puso en discusión problemáticas que les parecían específicas de su condición de género, entre ellas su situación de subordinación en la sociedad y la violencia que vivían en diversos ámbitos, principalmente en el privado. La invitación que hacían era "romper el silencio" y contar sus experiencias de manera colectiva. Estos ejes fueron centrales en el debate, la difusión y la elaboración de demandas (Huacuz y Saucedo, 2011). Si bien desde la $\mathrm{CEDAW}^{6}$ se habían nombrado algunas situaciones de abuso contra las mujeres, también es cierto que no se le nombraba como VCM, sino como discriminación.

\footnotetext{
${ }^{6}$ Convención sobre la eliminación de todas las formas de discriminación contra la mujer (CEDAW). Fue aprobada en 1979 pero su primera sesión fue en 1982. Puede observarse En el art. 6 un llamado a los Estados para "erradicar la trata y la explotación de la prostitución".

Revista Zona Franca- Centro de estudios interdisciplinario sobre las mujeres (CEIM)- Maestría poder y sociedad desde la perspectiva de género (MG), Rosario, Argentina. ISSN, 2545-6504 http://zonafranca.unr.edu.ar/index.php/ZonaFranca| Numero 24 (2016). 
Durante las primeras tres Conferencias Mundiales sobre la Mujer, realizadas en México (1975), Copenhague (1980) y Nairobi (1985), el movimiento de mujeres representado por ONGs feministas buscaban que se visibilizara la violencia en el ámbito familiar y que se reconociera que la violencia sexual estaba presente no sólo en los conflictos armados sino en la vida cotidiana de las mujeres. Sin embargo, el tema de VCM no obtuvo mucha relevancia, en vista de lo cual, durante la antesala de la II Conferencia Mundial de Derechos Humanos en junio de 1993 realizada en Viena, cambiaron la estrategia y comenzaron a resaltar que la VCM era un asunto generalizado y naturalizado en el mundo. Llevaron ante un Tribunal $^{7}$ los testimonios de 33 mujeres de diferentes partes del mundo que narraron sus experiencias relacionadas con la violencia que sufrían. Cabe mencionar que varios de estos testimonios estaban relacionados con agresiones sexuales en la cárcel, incesto, prostitución forzada, violación en el matrimonio o en contextos de conflictos armados (Miller, 2004). Los testimonios cumplieron su propósito y uno de los resolutivos fue considerar los derechos de las mujeres como derechos humanos universales y eliminar las prácticas que son "indignas con la valía de la persona humana” entre ellas, la explotación sexual (Reilly, 1994). Con ello, podrían instar a los gobiernos a intensificar sus esfuerzos a favor de la protección y la promoción de los derechos humanos de mujeres y niñas. Como consecuencia, en diciembre de ese mismo año, la Asamblea General de la ONU aprobó la Declaración sobre la Eliminación de la Violencia contra la Mujer. Con la influencia de estas discusiones previas y estos resolutivos, la Comisión de Derechos Humanos nombró en 1994 a su primera relatora

\footnotetext{
${ }^{7}$ En el marco del Tribunal organizado por el Center for Women's Global Leardships (ONG consultora que trabaja a favor de los DH de las mujeres y la justicia social.

Revista Zona Franca- Centro de estudios interdisciplinario sobre las mujeres (CEIM)- Maestría poder y sociedad desde la perspectiva de género (MG), Rosario, Argentina. ISSN, 2545-6504 http://zonafranca.unr.edu.ar/index.php/ZonaFranca| Numero 24 (2016). 
especial sobre la violencia contra la mujer. Su tarea era analizar las causas y consecuencias de la misma y rendir un informe de investigación sobre todos los aspectos de la violencia contra las mujeres (UNWOMEN). En 1994, la Comisión de la Condición Jurídica y Social de la Mujer $(\mathrm{CSW})^{8}$ fue la encargada de crear las condiciones para que, al siguiente año, el tema de la VCM fuera prioritario en la IV Conferencia Mundial sobre la Mujer realizada en Beijín. A partir de entonces la CSW realiza reuniones para dar seguimiento al cumplimiento de los acuerdos de Beijín y escuchar las problemáticas de las mujeres de diversas partes del mundo a través de las ONGs feministas que participan en las mismas ${ }^{9}$. Nace así una necesidad: encontrar expertas que manejen el lenguaje especializado de la VCM (ahora violencia de género) para que implementen planes y programas de monitoreo para combatirla y crear instituciones que transversalicen la perspectiva de género. Este sector del feminismo iberoamericano en los 90's ha sido llamado de diferentes maneras: feminismo profesionalizado (Álvarez, 1998), feminismo institucional (Lovenduski, 2007 y 2008; Valiente, 2007) y feminismo estatal (Matos y Paradis, 2013). Hacen referencia al proceso de oenegización e institucionalización, en el que las feministas se presentaban como expertas en temas de género, combate a la violencia y acceso a los derechos de las mujeres, con el propósito de obtener financiamientos de parte del Estado o de ONGs transnacionales. Hay que destacar que esto continúa hasta la

\footnotetext{
${ }^{8}$ Commission on the Status of Women (CSW). Creada por la ONU en 1947 pero con un papel activo contra la violencia desde 1996 para dar seguimiento a la Plataforma de Acción de Beijin. ${ }^{9}$ Para dar un ejemplo de las ONGs que participan ver: http://csonet.org/content/documents/E2014-INF-5\%20lssued.pdf
}

Revista Zona Franca- Centro de estudios interdisciplinario sobre las mujeres (CEIM)- Maestría poder y sociedad desde la perspectiva de género (MG), Rosario, Argentina. ISSN, 2545-6504 http://zonafranca.unr.edu.ar/index.php/ZonaFranca| Numero 24 (2016). 
actualidad, así como la estrategia de llevar el testimonio de las víctimas ${ }^{10}$ para que expongan sus experiencias, tanto en el marco de las reuniones internacionales por los Derechos Humanos como para testificar en juicios políticos. A continuación, se presentan dos ejemplos.

La última reunión de la CSW se realizó en marzo de 2016 en la Sede de Naciones Unidas de Nueva York y los temas a tratar fueron tres: el empoderamiento de la mujer, su vínculo con el desarrollo sostenible y la eliminación y prevención de todas las formas de violencia contra las mujeres y las niñas (conclusiones convenidas de la 57a sesión). Durante esta reunión, algunas ONGs llevaron a víctimas para que contaran su testimonio. Uno de ellos fue sobre explotación sexual, pero estuvo inscrito en el lenguaje de la violencia sexual. Es el caso de una joven mexicana que contó cómo había sido violada 43000 veces en cuatro años. Esta experiencia fue descrita por la directora de la ONG en un medio de comunicación y además agrega en la nota periodística:

Muchas personas pensarán que el enemigo más grande de esta causa son los tratantes, algunos políticos corruptos o los dueños de los giros negros. Sin embargo los peores enemigos, quizá para sorpresa de muchos, son las organizaciones de la sociedad civil coludidas con estos criminales (...) los países enfrentamos un fenómeno en común en la lucha contra la trata de personas: hay organizaciones de la sociedad civil financiadas por los seudo empresarios de la esclavitud. Éstas viven de la simulación, buscan confundir a la sociedad y frenar a los verdaderos activistas (Orozco, 2016).

Este ejemplo nos permite observar otro elemento presente en los discursos de las ONGs anti-trata: la lógica de deslegitimar la credibilidad de otras organizaciones que tienen posturas más flexibles sobre el sexo comercial y que no necesariamente entienden la prostitución como VCM. Puede verse

\footnotetext{
${ }^{10}$ Es conveniente aclarar que en este trabajo estamos entendiendo la categoría víctima como una construcción social que exalta la condición vulnerable, sufriente y doliente de los sujetos. Revista Zona Franca- Centro de estudios interdisciplinario sobre las mujeres (CEIM)- Maestría poder y sociedad desde la perspectiva de género (MG), Rosario, Argentina. ISSN, 2545-6504 http://zonafranca.unr.edu.ar/index.php/ZonaFranca| Numero 24 (2016). 
cómo se les señala como parte de los grupos criminales más peligrosos, un elemento nuevo en el paradigma de la victimización. De esta manera, la suma de testimonio de la víctima más la deslegitimación de otras organizaciones, intenta ser parte de la estrategia para sensibilizar a los organismos internacionales a través de la política de la compasión (Laínez, 2009; Fassin, 2012).

El segundo ejemplo es sobre la vigencia de la utilización del testimonio de las mujeres víctimas de violencia sexual, en el juicio que actualmente se está llevando a cabo contra el ex dictador Ríos Montt en Guatemala. En el informe de la Comisión de Esclarecimiento Histórico (CEH) patrocinado por la ONU, se han documentado más de 100 casos de violencia sexual de mujeres y niñas. En el juicio oral se han escuchado los relatos de las mujeres sobre las violaciones tumultuarias cometidas por parte de los soldados. Estas narraciones están al alcance de la opinión pública a través de los medios de comunicación (Elías, 2006). Pese a lo importante que es sin duda que se conozcan estos hechos, vale la pena reflexionar si los relatos de violencia sexual no están desviando el foco de atención de los factores políticos que propiciaron la dictadura guatemalteca.

\section{Violencia sexual y prostitución. La demanda de protección}

Es interesante en este punto, retomar el aporte de la feminista italiana Tamar Pitch (2003 y 2014) para entender el paradigma de la victimización, ya que es un concepto que explica por qué las demandas feministas se inscriben en la lógica del lenguaje penal. La autora reflexiona sobre la aparición de este paradigma y su utilización por el activismo político y social para exigir sus 
demandas. También analiza de qué manera el lenguaje del derecho penal pareciera utilizarse como resolutivo de una política en nombre de la justicia social. Asimismo, describe el giro discursivo del movimiento feminista, ya que en un primer momento señalaba como responsable de su condición a la "opresión", la cual estaba compuesta multifactorialmente (contexto social, político y cultural) y posteriormente giró hacía el "paradigma de la victimización" que implica una situación. Esta última ubica la responsabilidad en los individuos, por ello son tan útiles las demandas de ampliación de penas. Dicha visión trae aparejada además la idea de que los fenómenos sociales se resuelven en el ámbito de lo jurídico, de tal manera que: "[L]a demanda de la actuación del derecho penal [actúa como] instrumento de política social" (Pitch, 2003:130).En un trabajo posterior, la autora profundiza sobre el uso político del término VCM, argumentando que dicha lógica requiere de personas que necesiten ser salvadas/rescatadas y de victimarios que sean criminalizados. También explica cómo, a través de la VCM, el gobierno justifica sus intervenciones en nombre de la seguridad y la defensa de las personas vulnerables. En este sentido, utiliza el ejemplo de las luchas contra los inmigrantes:

Cada vez que un inmigrante acosa o viola a una mujer, o cada vez que un inmigrante pega a la hija que se rebela contra la tradición, se exige la aplicación de medidas severas y se libera la retórica contra la barbarie extranjera (olvidando que la mayor parte de la violencia contra las mujeres es obra de italianos, normalmente de hombres cercanos a las víctimas (2004: 24).

Uno de los elementos más importantes de su aporte es la reflexión sobre la variación en la utilización de términos que se refieren a la VCM. De esta manera, VCM fue sustituido por violencia de género, y aunque esta acepción daba cuenta de la violencia sufrida tanto por la condición de ser mujer o varón, 
en la práctica común se resignificó discursivamente como sinónimo de VCM. Cabe mencionar que la violencia de género condensa actualmente todas las formas de violencia contra las mujeres y es el término más utilizado políticamente. Se observa un énfasis en resaltar la violencia sexual a través de sus diversas manifestaciones y en sus diferentes contextos.

El hincapié sobre la violencia sexual hace recordar otro momento histórico en los años 80's, en el que algunas feministas norteamericanas habían debatido sobre considerar o no la pornografía y la prostitución como expresiones de VCM (Ferguson, 1984; Osborne, 1988; McKlintock, 1993; Piscitelli, 2008; Prada, 2010). Posteriormente, a comienzos de los 90's algunas ONGs religiosas y feministas que protagonizaron "la cruzada contra la trata y el trabajo sexual" en Estados Unidos ${ }^{11}$ aprovecharon la reactualización de dichos debates y empezaron a construir la relación entre prostitución, explotación sexual y trata. Los políticos y la derecha religiosa, principalmente los cristianos evangélicos, aprendieron el lenguaje de los derechos humanos y unieron fuerzas con el feminismo radical que buscaba vincular la prostitución como forma de VCM a través de las políticas contra la trata (Bernstein, 2010). Mientras tanto, algunas feministas radicales volvieron a relacionar a la prostitución "como el espacio más espantoso donde se produce el daño sexualizado con marca de género" (Barry, 1995 en Miller, 2004). Representaban la prostitución como violación y a las víctimas como mujeres jóvenes, inocentes, que habían sido engañadas, se prostituían en contra de su voluntad y no obtenían ninguna ganancia. Para comprobar la actualidad de

\footnotetext{
${ }^{11}$ Ver más sobre esta retrospectiva sobre ONG que participaron en este debate en Weitzer, 2015.

Revista Zona Franca- Centro de estudios interdisciplinario sobre las mujeres (CEIM)- Maestría poder y sociedad desde la perspectiva de género (MG), Rosario, Argentina. ISSN, 2545-6504 http://zonafranca.unr.edu.ar/index.php/ZonaFranca| Numero 24 (2016). 
estos argumentos, basta regresar a mirar el ejemplo antes citado sobre el testimonio presentado en la CSW en que prostitución es sinónimo de violación.

\section{Perspectiva penal y sanitaria en el caso de la política anti-trata}

Durante los últimos treinta años el movimiento de mujeres se ha centrado en la atención y lucha por la erradicación de la VCM. Sus demandas han sido inscritas principalmente bajo dos perspectivas: penal y sanitaria. En primer lugar, la penal contempla mecanismos de seguimiento legal que derivarían en un feminismo punitivo (Larrauri, 2007) o feminismo carcelario (Bernstein, 2014) en el caso específico de las políticas anti-trata. Bernstein (2014) explica que el"giro carcelario" de la política feminista estadounidense, que antes promovía la liberación personal y la justicia humana, ahora está comprometido con la agenda carcelaria, la cual es una práctica más de gobernanza del Estado neoliberal. Además, analiza el caso del papel de las políticas impulsadas por el feminismo en temas de sexualidad, a través de dos elementos: la revisión de trabajos provenientes de la sociología, jurisprudencia y de la teoría feminista para observar el modo en que se han inscrito en la política punitiva estadounidense actual; y su trabajo de campo etnográfico, académico y político de más de diez años, para analizar su impacto. Da cuenta de la forma en que, por un lado, los temas referentes a derechos reproductivos tienen una visión más liberacionista, en comparación con todo lo que se considera violencia sexual, incluido el sexo comercial y la trata de personas, cuyo enfoque es criminal. Profundiza particularmente en la política anti-trata y su inscripción en los discursos neoliberales que combaten el "crimen organizado" con ayuda del feminismo hegemónico norteamericano. Cuestiona la manera poco crítica de ver cuáles han sido las consecuencias en cuanto al Revista Zona Franca- Centro de estudios interdisciplinario sobre las mujeres (CEIM)- Maestría poder y sociedad desde la perspectiva de género (MG), Rosario, Argentina. ISSN, 2545-6504 http://zonafranca.unr.edu.ar/index.php/ZonaFranca| Numero 24 (2016). 
control del cuerpo de las mujeres por parte del Estado a través del discurso de la protección. Asimismo, señala que "el discurso de los derechos humanos se volvió un vehículo clave para la transnacionalización de las políticas carcelarias bajo una apariencia de feminismo benevolente" (Bernstein, 2014:282).

En concordancia con lo anterior, hay que resaltar que las luchas para erradicar la VCM (después violencia de género) retomaron la prostitución como forma de violencia sexual, y esto influyó en las discusiones previas para la creación e implementación de instrumentos legales y políticas públicas contra la trata de personas que, de alguna manera, también actúan contra la prostitución. Tal es el caso del "Protocolo para Prevenir, Reprimir y Sancionar la Trata de Personas, Especialmente Mujeres y Niños"(también conocido como Protocolo de Palermo, firmado en el año 2000) ${ }^{12}$. Este Protocolo surgió después de una serie de reuniones en Viena, en las que grupos enfrentados de feministas discutieron la definición de trata. Forma parte(junto con otros $\operatorname{dos}^{13}$ )de la Convención de Naciones Unidas contra la Delincuencia Organizada Transnacional. Tanto el Protocolo como la Convención fueron impulsados por la Oficina de Naciones Unidas contra la Droga y Delito creada con el objetivo de controlar la criminalidad. Es importante decir, en este sentido, que no fue creado en el marco de garantizar derechos a las mujeres. Algunos ejemplos muestran la manera en que los testimonios de las víctimas han resultado

\footnotetext{
${ }^{12}$ Define la Trata de personas como: [L]a captación, el transporte, el traslado, la acogida o la recepción de personas, recurriendo a la amenaza o al uso de la fuerza u otras formas de coacción, al rapto, al fraude, al engaño, al abuso de poder o de una situación de vulnerabilidad o a la concesión o recepción de pagos o beneficios para obtener el consentimiento de una persona que tenga autoridad sobre otra, con fines de explotación. Esa explotación incluirá, como mínimo, la explotación de la prostitución ajena u otras formas de explotación sexual, los trabajos o servicios forzados, la esclavitud o las prácticas análogas a la esclavitud, la servidumbre o la extracción de órganos.

${ }^{13}$ Protocolo contra el Contrabando de Migrantes por Tierra, Mar y Aire y el Protocolo contra la fabricación y el tráfico ilícito de armas de fuego.
}

Revista Zona Franca- Centro de estudios interdisciplinario sobre las mujeres (CEIM)- Maestría poder y sociedad desde la perspectiva de género (MG), Rosario, Argentina. ISSN, 2545-6504 http://zonafranca.unr.edu.ar/index.php/ZonaFranca| Numero 24 (2016). 
fructíferos a la hora de conseguir financiamiento internacional. Es interesante recordar el caso de la activista camboyana Somaly Mam quien se presentaba como ex víctima de trata y creó su propia organización. Por mucho tiempo obtuvo premios y recursos económicos para su ONG, que se convirtió en una de las organizaciones anti-trata más millonarias en el mundo. Posteriormente se descubrió que sus testimonios habían sido falsos ${ }^{14}$ (Vidal, 2014; Galindo, 2014; Gatti, 2016).

Continuando con el argumento anterior, que articula la prostitución exclusivamente a través del lente de la violencia, se considera importante analizar la proliferación de normativas a nivel internacional en nombre de la protección de las mujeres. Paradójicamente, éstas han sido utilizadas para justificar restricciones estatales de derechos, tal es el caso de la migración y el ejercicio del sexo comercial. Por ejemplo, en Nepal las mujeres de menos de treinta años no pueden salir de sus países sin el permiso de su esposo o tutor (Kapur, 2006); las africanas son deportadas desde Francia a sus países para protegerlas del "peligro de la trata" (Guillemaut, 2004); las brasileñas son criminalizadas si intentan migrar a Europa con el objetivo insertarse en el comercio sexual (Silva, Blanchette y Bento en Piscitelli y Lowenkon, 2015);y algunas trabajadoras sexuales argentinas son violentadas institucionalmente en los operativos de búsqueda de víctimas de trata (Varela y Daich, 2014). Las políticas anti-trata tienen el discurso de controlar, observar y castigar en nombre de la protección de las víctimas. Lo curioso es, como dice Claudia Aradau (2009), que en realidad nunca hubo un consenso sobre lo que

\footnotetext{
${ }^{14}$ Las investigaciones que se realizaron descubrieron que era falsa su historia sobre esclavitud sexual, el asesinato de ocho mujeres por el ejército camboyano y el supuesto secuestro de su propia hija por las redes de trata. Posteriormente Somaly Mam aceptó que había inventado esta información.

Revista Zona Franca- Centro de estudios interdisciplinario sobre las mujeres (CEIM)- Maestría poder y sociedad desde la perspectiva de género (MG), Rosario, Argentina. ISSN, 2545-6504 http://zonafranca.unr.edu.ar/index.php/ZonaFranca| Numero 24 (2016). 
significaba la protección. Ante la ambigüedad de ese concepto, puede verse cómo las ONGs anti-tráfico terminaron invocando en sus discursos sobre acceso a derechos humanos el derecho de las mujeres a ser "salvadas":

El imperativo de la salvación se confunde con la gobernanza de la vida que no es nada más que una gobernanza de los sujetos (...) Los derechos de las víctimas del tráfico se convierten en los derechos de las ONGs para moldear y tratar a las mujeres. Se convierte en los derechos de las agencias internacionales para intervenir en la vida de las víctimas (Aradau, 2009:241).

En contraparte, las ONGs que no deciden alinearse con este modelo experimentan repercusiones mediante la limitación de financiamientos, puesto que se les imponen lineamientos e incluso posicionamientos particulares. Cecilia Varela (2015) cita el ejemplo del caso brasileño. Describe la renuncia de las organizaciones que realizaban intervenciones de prevención y atención al $\mathrm{VIH} / \mathrm{SIDA}$ con trabajadoras sexuales, a un financiamiento en 2005 de 40 millones de dólares porque la United States Agency for International Developmente (USAID) pedía como requisito para mantenerlo manifestarse en contra del trabajo sexual y su legalización. En cambio, otorgó el financiamiento a organizaciones de base religiosa que no sólo se posicionaron en contra de la prostitución, sino que tenían que invertir el 33\% del mismo en la "promoción de la abstinencia hasta el casamiento y el reforzamiento de la fidelidad matrimonial” (Varela, ídem.:117-118).

Por otro lado, pero siguiendo la lógica de la protección, la demanda de políticas carcelarias va acompañada de la demanda de reconocimiento a las consecuencias físicas y emocionales que provocaba la VCM. En este sentido, se instala la perspectiva sanitaria que promovió un sistema especializado para asistir médica y psicológicamente a las sobrevivientes de violencia. Las 
feministas estatales de diversos países que dirigían oficinas o programas para la atención de mujeres, sobre todo violencia familiar y sexual, ahora eran especialistas en lenguaje del género y la violencia. Pronto comenzaron a pedir medidas de atención a las víctimas que incluyeran casi unitariamente en los servicios de asistencia médica y psicológica. Esta perspectiva sanitaria tuvo un alcance importante y en 1996 la Organización Mundial de la Salud (OMS) reconoció la VCM como un problema de salud pública. A partir de entonces, comenzó un despliegue de políticas públicas con enfoque sanitario en los contextos locales. Sus tareas consistían en realizar sensibilización, capacitación para prevenir e identificar la violencia, así como atenderla, principalmente ayudando a las mujeres a reconocer la violencia que vivían y atendiendo las secuelas psico emocionales de la misma.

Diddier Fassin (2012) ha documentado el viraje de los objetivos de un sub rama de la psicología, la victimología, la cual basaba su interés en las causas de la violencia y posteriormente en las consecuencias de la misma. De la misma manera, el autor identifica cómo en las últimas décadas, sobre todo a partir de los años 90's la violencia fuere significada y traducida al idioma de la salud mental, a través de la categoría "trauma". Recalca que los discursos de las víctimas, acerca de sus experiencias dolorosas en diferentes tipos de conflicto político, están por encima de los análisis que intenten explicar las causas estructurales que provocaron dicho sufrimiento. También explica cómo actualmente las personas más legitimadas para hablar ya no son los "sobrevivientes" de los conflictos para brindar su testimonio, sino los especialistas que tienen contacto con esos/esas sobrevivientes. En el mismo sentido, Alice Miller (2004) sostiene que la voz de los especialistas suplió las 
voces de las activistas feministas que hablaban a favor de los derechos de las niñas y las mujeres. Ahora se prioriza la voz de las/los expertos en medicina y psicología en los debates públicos sobre sexualidad. Esta perspectiva sanitaria considera a las mujeres seres pasivos a los que hay que evaluar y diagnosticar. "[L]o que está en juego no es la vida de las víctimas [ni su seguridad] si no su autonomía" (Laínez2009:313). Incluso, va un poco más allá. Los especialistas recomiendan las acciones o intervenciones que tienen implicancia directa sobre la vida de las mujeres y validan o invalidan sus relatos dependiendo de la interpretación de las problemáticas. Por ejemplo, si las mujeres defienden su participación en la prostitución de manera voluntaria, estas políticas no la toman en cuenta porque consideran que esta actividad es VCM y ninguna persona puede consentir su explotación. Para invalidar su relato, lo describen como poco creíble o hablan de un síndrome de falsa conciencia o discurso aleccionado. Las únicas mujeres a las que se les cree son aquellas que manifiestan estar "arrepentidas", aquellas que han sido llamadas sobrevivientes (Jessen, 2004).

\section{Para seguir reflexionando. Criticas y consecuencias del discurso de}

\section{la VCM}

Sin duda en el balance sobre el reconocimiento de la VCM hay beneficios y consecuencias no tan positivas. Algunas de las ventajas fueron la creación de espacios para atender las consecuencias de la violencia familiar y sexual e incluso, en algunas latitudes, sobre todo de países europeos, se crearon centros de apoyo a las trabajadoras sexuales o bien, se pudo acceder al aborto (Jessen, 2004). 
También estas políticas dieron pie para exigir a los Estados el respeto a los derechos de las mujeres y propiciaron las discusiones jurídicas acerca de la violación, la violencia de pareja y el abuso sexual. Otro aporte importante fue la creación de categorías para poder diferenciar los tipos de violencia, aunque en dicho intento se contemplaran elementos muy subjetivos. Tal es el caso, por citar un ejemplo, de la Ley General de Acceso a una Vida Libre de Violencia que surge en el año 2007 en México. Una Ley penal que consideraba violencia psicológica a:

...cualquier acto u omisión que dañe la estabilidad psicológica, que puede consistir en: negligencia, abandono, descuido reiterado, celotipia, insultos, humillaciones, devaluación, marginación, desamor, indiferencia, infidelidad, comparaciones destructivas, rechazo, restricción a la autodeterminación y amenazas, las cuáles conllevan a la víctima a la depresión, al aislamiento, a la devaluación de su autoestima e incluso al suicidio (LGAMVLV, 2007).

El término "desamor" tuvo que ser suprimido en 2014con el argumento de que era subjetivo para la interpretación de los jueces, pero prevalecieron otros términos igual de subjetivos en la misma definición, tal es caso de indiferencia, infidelidad, comparaciones destructivas, rechazo y restricción a la autodeterminación (LGAMVLV, 2014).

Por otro lado, las críticas sobre la VCM como estrategia de reconocimiento y lucha política, tienen en común la generalización tanto de las mujeres, como de sus experiencias y contextos. En primer lugar, se cuestiona que se hable en nombre de "las mujeres" como sujetos homogéneos, ignorando cuestiones específicas que tienen que ver con ubicación geográfica, clase, etnia, religión, orientación sexual entre otras (Moore, 1991; Lamas, 2000). Además de que esta generalización minimiza e invisibiliza las preocupaciones políticas de las mujeres subalternizadas con demandas particulares, así como sus estrategias de resistencia (Mohanty, 2008). 
Las críticas también tienen que ver con la visión binaria y simplista de las relaciones entre personas, en la que las mujeres siempre son víctimas de los varones. En esta representación las “mujeres” aparecen como sujetos-víctimas, definidas como ignorantes, pobres, sin educación, limitadas por las tradiciones culturales y restringidas al ámbito doméstico (Kapur, 2006).

Más allá de la simple mención de las potencialidades y límites que han producido estas políticas, nos parece importante relacionarlas siempre con investigaciones empíricas. En ese sentido y sólo para dejar abierta una futura línea de investigación, hay que señalar que algunas políticas se nutrieron principalmente de los discursos que articulaban violencia de diferente índole con acceso a Derechos Humanos pero en el marco de políticas criminales. Lejos de garantizar el acceso a la justicia social de las mujeres, contribuyeron al control de las mismas, por ejemplo el caso de la política anti-trata.

Resumiendo lo que ha sido planteado hasta el momento, el movimiento de mujeres representado por ONGs feministas supo aprovechar el momento histórico para utilizar los testimonios de las víctimas de violencia y posicionar algunas de sus demandas en las esferas políticas. El lenguaje que retomó la VCM de los juicios del holocausto fue víctimas, sobrevivientes, una invitación a romper el silencio sobre las experiencias traumáticas y el testimonio en clave de sufrimiento.

Esta estrategia contribuyó a que los organismos de derechos humanos no sólo reconocieran la VCM sino que algunas instituciones a nivel local proporcionaran fondos para la implementación de políticas de prevención, creación de programas y especialización de profesionales para atención a víctimas de VCM (después violencia de género). A nivel político, las demandas 
de las ONGs feministas se han concentrado en dos perspectivas: penal, que pide la ampliación de penas para los agresores de las mujeres, y sanitaria, que gestiona programas y profesionales especializados para atención física y mental de las víctimas de violencia de género. Ambas funcionaron bajo la premisa de garantizar la igualdad de oportunidades y derechos. Algunas de las críticas al respecto han sido la generalización de las mujeres y sus experiencias, así como las consecuencias de ver a las mujeres como sujetosvíctimas, pues se les equipara con niños/as que necesitan protección y tutela. Esta mirada ha ocasionado que se invisibilicen sus resistencias y se minimicen sus voces en cuánto a lo que necesitan. Otra de las críticas tiene que ver con el papel de los especialistas que hablan en nombre de las víctimas y la sobreexposición que se realiza de ellas para que brinden sus testimonios, los cuales siguen utilizándose para visibilizar demandas, mucha de ellas de índole penal. También se citaron algunos casos en los que puede observarse cómo en nombre de la protección se controla la movilidad y accionar de las mujeres. En este sentido, será interesante preguntarse si las políticas respaldadas por el feminismo institucional realmente están contribuyendo a la erradicación de la violencia o si éstas, por el contrario, están generando un efecto paradójico en la vida de las mujeres al exponerlas como sujetos sufrientes y sin voz propia.

\section{Bibliografía}

AGUSTíN, Laura (2003) "Olvidar la victimización: los migrantes como protagonistas”, en Development, N³, V. 46, pp. 30-36

ÁLVAREZ Sonia (1998) "Neoliberalismos y trayectorias de los feminismos latinoamericanos", en América Latina en Movimiento, № 6, V.2, pp. 265-284 
ARADAU, Claudia (2009) "Vida, derechos y riesgos: las paradojas del tráfico de personas". En Nicolás Lazo, Gemma; Bodelón González, Encarnación y Bergalli, Roberto (eds.) Género y dominación. Críticas feministas del derecho y el poder, Anthropos, Barcelona, pp. 233-246

BERNSTEIN ELIZABETH (2014) “¿Las políticas carcelarias representan la justicia de género? La trata de mujeres y los circuitos neoliberales del crimen, el sexo y los derechos", en Debate Feminista. Veinticinco años, cincuenta números. Dossier: Comercio sexual, Año 25, №.50, México, pp. 280320

(2010) "Militarized humanitarianism meets carceral feminism: The politics of sex, rights, and freedom in contemporary antitrafficking campaigns", en Signs, V. 1, N 36 , pp.45-71

BLANES, Jaume (2011) "Hubo un tiempo no tan lejano... Relatos y estéticas de la memoria e ideología de la reconciliación", en Revista de Teoría de la Literatura y Literatura comparada, $\mathrm{N}^{\circ} 4$, pp. 35-55

BLANES, Jaume y Germa, PALAZÓN (2015) Avatares del testimonio en América Latina: tensiones, contradicciones, relecturas... En Kamchatka: revista de análisis cultural, $\mathrm{N}^{\circ} 6$.; España.

CALVEIRO, Pilar (2006) "Testimonio y memoria en el relato histórico", en Acta Poética, V. 2,№27

CEDAW, consultado en http://www.un.org/womenwatch/daw/cedaw/text/ sconvention.htm

Center for Women's Global Learderships, consultado en http://www.cwgl.rutgers.edu).

CHEVALIER, Yves (2000) "WIEVIORKA (Annette), L'Ėre du témoin”, en Archives de sciences sociales des religions, $\mathrm{N}^{\circ} .2$, pp.53-53

CSW (Commission on the Status of Women), consultado en http://www.unwomen.org/es/csw/csw60-2016

ELÍAS, José (2016) Mujeres violadas en Guatemala relatan el horror sufrido. En El País, 4 de abril

EMMELHAINZ, Irmgard (2015) La vulnerabilidad, una nueva teoría del poder, en Nexos, México, 25 de noviembre, consultado en http://cultura.nexos.com.mx/?p=9426\#_ftnref8

FASSIN, Diddier (2012) Humanitarian reason: a moral history of the present. University of California Press, California 
FASSIN, Diddier (2008) "The humanitarian politics of testimony: Subjectification through trauma in the Israelí-Palestinian conflict", en Cultural Anthropology, $\mathrm{N}^{\circ} 23, \mathrm{~V} .3$, pp.531-558

FERGUSON, Ann (1984) "Sex War: The debate between Radical and Libertarian Feminists", en Signs, V. 10, N¹, pp. 106-112

GALINDO, Cristina (2014) Vida inventadas, El País, España, 7 junio

GARCÍA, Carmen y VALDIVIESO, Magdalena (2005) "Una aproximación al Movimiento de Mujeres en América Latina", en OSAL, CLACSO, V.18, $\mathrm{N}^{\circ} 6$, pp.41-56

GATTI, Gabriel (2003) "Las modalidades débiles de la identidad. De la identidad en los territorios vacíos de sociedad (y de sociología)", en Política y Sociedad, V.1, N40, pp. 87-109

(2015) "Tiene [la] palabra la víctima pura[?]El vacío social, el testimonio y la desesperación del investigador ante el sufrimiento sin forma ni lenguaje", en Kamchatka. Revista de análisis cultural, N 6

(2016) "El misterioso encanto de las víctimas", en Revista de Estudios Sociales, Universidad de los Andes, Colombia, N 56, pp.117-120

HUACUZ, Guadalupe \& SAUCEDO, Irma (2011) "Movimientos contra la violencia hacia las mujeres". En Un fantasma recorre el siglo. Luchas feministas en México, Ítaca, UAM, pp.213-243

JESSEN, Liv (2004) "Prostitution seen as violence against women", en Sex work, mobility and health in Europe, editado por Sophie Day y Helen Ward, London

KAPUR, Ratna (2002) "The Tragedy of Victimization Rhetoric: Resurrecting the Native Subject in International/Postcolonial Feminist Legal Politics", en Harvard Human Rights Law Journal, Vol. 15

(2006) "Human rights in the 21st century: Take a walk on the dark side”, en Revista Sydney L.., N²8, pp. 665

LAINÉZ, Nicolás (2009) “¿Representar la explotación sexual? La víctima puesta en escena", en Revista de Antropología Social, V.18, Universidad Complutense de Madrid, España, pp. 297-316

LAMAS, Marta (2000) "De la identidad a la ciudadanía", en Cinta moebio, $N^{\circ} 7$, pp. 18-23. Consultado en www.moebio.uchile.cl/07/lamas.htm

LGAMVLV (2007) Diario Oficial de la Federación, consultado en http://www.diputados.gob.mx/LeyesBiblio/ref/lgamvlv/LGAMVLV_orig_01feb07. pdf 
LARRAURI, Elena (2007) Criminología crítica y violencia de género, Editorial Trotta, Madrid

LOVENDUSKI, Joni (2007) The New Politics of Gender Equality, Palgrave Macmillan, Basingstoke

(2008) "State Feminism and Women's Movements", en West European Politics, №31, pp.169-194

MATOS, Marlise y PARADIS, Clarisse (2013)"Los feminismos latinoamericanos y su compleja relación con el Estado: debates actuales", en/conos: Revista de Ciencias Sociales, № 45, pp. 91-107

MCKLINTOCK, Anne (1993) "Sex workers and sex work", Introduction, en Social Text, $\mathrm{N}^{\circ} 37$, pp.1-10

MÈLICH, Joan-Carles (2001) "La ausencia del testimonio: ética y pedagogía en los relatos del Holocausto", en Anthropos, V. 2

MILLER, Alice (2004) "Sexuality, violence against women, and human rights: women make demands and ladies get protection", en Health and Human Rights, V.7, № 2, pp. 16-48

MOHANTY, Chandra (2008) "Bajo los ojos de Occidente. Saber académico y discursos coloniales". En Liliana Suárez Navaz y Aída Hernández (editoras), Descolonizando el Feminismo : Teorías y Prácticas desde los Márgenes, Editorial Cátedra, Madrid

MOORE, Henrrietta (1991), Antropología y feminismo, Universitat de València, Valencia

OMS, consultado en http://www.who.int/mediacentre/factsheets/fs239/es/

OROZCO, Rosi (2016) Karla fue violada más de 43000 veces en cuatro años, Milenio diario, 25 de marzo

OSBORNE, Raquel (1988) Debates actuales en torno a la pornografía y la prostitución, en Papers. Revista de Sociología,№. 30, pp. 97-107

PISCITELLI, Adriana (2008) "Entre as "mafias" e a "ajuda" a construção de conhecimento sobre trafico de pessoas", en Cadernos Pagu, $\mathrm{N}^{\circ} 31$

PISCITELLI, Adriana y LOWENKON, Laura (2015) "Trabajadoras sexuales, policía, migración y trata internacional de seres humanos en Brasil y España". En Daich, Deborah y Sirimarco, Mariana (comp.) Género y violencia en el mercado del sexo. Política, policía y prostitución, Editorial Biblos, Buenos Aires, pp.173-204 
PITCH, Tamar (2003). Responsabilidades limitadas: Actores, conflictos y justicia penal, Editorial AH-HOC, Buenos Aires

(2014) "La violencia contra las mujeres y sus usos políticos", en Anales de la Cátedra Francisco Suárez, V. 48, pp. 19-29

PRADA, Nancy (2010) “¿Qué decimos la feministas sobre la pornografía? Los orígenes de un debate, en Manzana de Discordia, V. 1, $\mathrm{N}^{\circ} 5$

REILLY, Niamh et. al. (1994) "Testimonies of the Global Tribunal on Violations of Women's Human Rights at the United Nations World Conference on Human Rights: Vienna, June 1993". En Niamh Reilly (comp.) Center for Women's Global Leadership, Douglass College

UNWOMEN, consultado en http://www.unwomen.org/es/csw/brief-history

VALIENTE, Celia (2007) "Developing Countries and New Democracies Matter. An Overview of Research on State Feminism Worldwide", en Politics \& Gender, Año 3, N 4

VARELA, Cecilia (2015) "La campaña anti-trata en la Argentina y la agenda supranacional". En Daich, Deborah y Sirimarco, Mariana (comp.) Género y violencia en el mercado del sexo. Política, policía y prostitución, Editorial Biblos, Buenos Aires

VARELA, Cecilia\& DAICH, Deborah (2014) "Entre el combate a la trata y la criminalización del trabajo sexual: Las formas de gobierno de la prostitución", en Delito y Sociedad. Revista de Ciencias Sociales, Universidad Nacional del Litoral, Año 23, Nº 38, pp.63-86

VIDAL, Macarena (2014) Dimite Somaly Mam al destaparse falsedades en su autobiografía, El País, España, 30 mayo de 2014

WEITZER, Ronald (2014)“El movimiento para criminalizar el trabajo sexual en Estados Unidos", en Debate Feminista. Veinticinco años, cincuenta números. Dossier: Comercio sexual, № 50 , pp. 187-219 